\title{
Radon signals at the Roded site, Southern Israel
}

\author{
G. Steinitz and O. Piatibratova \\ Geological Survey of Israel, 30 Malkhe Israel St., Jerusalem 95501, Israel
}

Received: 18 May 2010 - Published in Solid Earth Discuss.: 22 June 2010

Revised: 19 September 2010 - Accepted: 6 October 2010 - Published: 16 November 2010

\begin{abstract}
Temporal variations of radon in the geological environment (upper crust) are frequent and recognized as unique in terms of the signals encountered and for the lack of substantial and generally applicable explanations. The phenomena observed at the Roded site, located in arid southern Israel, illustrate this situation. The monitoring of radon in the last 10 years or more has been carried out in massive meta-diorite of the Precambrian basement block of Roded. The measurement is conducted using an alpha detector at a resolution of 15-min, placed in a borehole at a depth of $9 \mathrm{~m}$, within a PVC casing to that depth. Systematic temporal variation patterns, manifested as large relative signals are composed of sub-diurnal (SDR) radon, multi-day (MD) and annual (AR) signals. The overall variation is dominated by the intense SDR signals which occur in some days, and may vary from background levels (5 counts or less) to peak values (attaining $>1000$ counts) and back to background at an interval of 6 to $12 \mathrm{~h}$. Intervals of up to several tens of days without significant SDR signals interchange with times of intense daily occurrences of such signals. Their occurrence indicates very fast variations of radiation from radon at the point of measurement. The peak times, within the diurnal 24-h cycle of SDR signals occur preferentially at an interval of 14-16 h (UT+2). Spectral analysis indicates: (a) A diurnal periodicity composed of a primary $24-\mathrm{h}$ and a secondary 12-h periodicity, which are attributed to the solar tide constituents S1 and S2. Tidal constituents indicative for gravity tide (O1, M2) are lacking; (b) An annual periodicity. A compound relation among the diurnal and annual periodicity is indicated by: (a) Continuous Wavelet Transform (CWT) analysis shows an overall annual structure with a modulation of the S1 and S2 periodicities; (b) Moving-time-window Fourier spectral analysis showing that the amplitudes of $\mathrm{S} 1$
\end{abstract}

Correspondence to: G. Steinitz (steinitz@gsi.gov.il) and S2 vary in an annual pattern, with relatively high values in summer. The phase of S1, S2 and S3 shows a systematic multi-year variation. It is suggested that the significant signatures of the periodic phenomena and their modulations reflect a direct link with the solar radiation tide.

\section{Introduction}

Radon $\left({ }^{222} \mathrm{Rn}\right)$, being a radioactive inert gas formed by disintegration from ${ }^{226} \mathrm{Ra}$, is a unique trace gas component in the natural environment. It occurs at varying concentrations in geological environments, mostly unsupported by radium, and very often shows large, complex and systematic temporal variations. These features of variation are supposed to reflect natural processes in subsurface systems. The suggested drivers and influences include primarily: (a) geo-mechanical processes acting on the rate of release of radon from the solid substrate into the fluid phase; and/or influences on the level of radon in the fluid phase - either via (b) mechanical stress and strain on the surrounding rock system, or (c) above surface atmospheric influences on the transfer of radon in geogas $^{1}$, in the subsurface environment; (d) interaction and mass transfer with above surface atmospheric environment; (e) adsorption and desorption processes. One of the important and frequent motivations for the investigation, of its temporal variation in the geological environment, is its potential use as a proxy of active subtle geodynamic processes, mainly seismogenic and volcanic.

It is often assumed that the temporal patterns of radon in the geogas phase are due to processes affecting its exhalation from the country rock and/or gas transfer processes in the complex consisting of rock porosity and subsurface air space.

\footnotetext{
${ }^{1}$ Geogas = gaseous phase in the unsaturated zone above the groundwater level, sometimes incorrectly referred to as "soil air" or "soil gas".
} 
Environmental influences, particularly atmospheric pressure and temperature, have been proposed for the origin of the periodic signals observed in radon time series (Shapiro et al., 1985; Ball et al., 1991; Pinault and Baubron, 1997; Finkelstein et al., 2006). However, other studies (Aumento, 2002; Groves-Kirby et al., 2006; Crocket et al., 2006; Weinlich et al., 2006) indicate that a consistent meteorological influence cannot be identified as giving rise to variability in radon time series, and suggest gravitational tides as an influencing factor on radon variability, since both earth tides and ocean tidal loading may drive periodic radon exhalation via crustal expansion/compression and geophysically driven groundwater level variations.

The application of stress to rocks is thought to enhance the exhalation of radon from the solid mineral phase, rendering radon a potential sensitive tracer of geodynamic processes in the upper crust. Transport of radon in soil and water has been investigated as a tool for monitoring volcanic activity (e.g. Cigolini et al., 2001, 2009; Burton et al., 2004; Alparone et al., 2005; Immè et al., 2006). The proposition that radon may serve as a useful proxy for seismic activity has been repeatedly raised (e.g. Monin and Seidel, 1992; Segovia et al., 1995; Toutain and Baubron, 1999; Hartmann and Levi, 2005, and references therein). Trique et al. (1999), using measurements in a tunnel within massive gneiss, associated multiday Rn bursts with transient deformation due to loading and unloading of a local water reservoir. Despite the presumed advantages of radon as a geophysical proxy, the utilization of radon in geodynamics has been hampered by the complex patterns of the measured signals (for a recent review see Cicerone, 2009).

So far establishing the geodynamic nature of such signatures and signals in radon time series relies on the negation of atmospheric influence, analysing radon signatures in the geological, spatial, time and frequency domains, and primarily by establishing a correlation with geophysical phenomena, and specifically the correlation to earthquakes. In general, the understanding of the nature and the processes driving the formation of radon signals in subsurface geogas is uncertain and disputed. The diversity of the observations, the complexity of the phenomena and the span of the suggested mechanisms render the overall picture as unresolved, hampering utilization of radon as a significant proxy of geodynamic processes.

The monitoring of Rn has been performed since 1995 in the frame of the Israel Geophysical Radon Project (IGRnP) in upper crustal rock systems from the Dead Sea to the Gulf of Aqaba. Several signal types are recognized, recurring in time and at different stations, ranging from multi-year to subdiurnal scales which are periodic and non-periodic (Steinitz et al., 1992, 1996, 1999, 2007). Following the prevailing approaches and models it was attempted to determine the potential of non-periodic signals as a proxy of active seismically related geodynamics (Steinitz et al., 2003; Begin and Steinitz, 2005). Further effort to advance along this track did not result in progress, and on the other hand it became clear that an overall understanding of the unique behaviour of radon was required, and specifically the driver(s) of the associated periodic signals. Barbosa et al. (2007) demonstrated that radon time series exhibit non-stationary features in both mean and variance and clear nonlinear characteristics. Detailed and advanced geophysical analysis of the radon phenomena at two key sites (Steinitz et al., 2007; Steinitz and Piatibratova, 2010) demonstrated that: (a) the large scale of relative variation of the superimposed signals and the temporal structure of the data is characteristic (unique) for radon time series in the subsurface; (b) the periodic and non-periodic patterns in radon time series display compound patterns of variation spanning multi-years to several hours; (c) local atmospheric influences cannot explain the observed patterns, and (d) the signals cannot be explained in term of known local active geodynamics. The outcome of the results from the field sites in Israel indicate that unrecognized dynamic processes are driving the radon signal in the geogas in the subsurface to a depth of about $100 \mathrm{~m}$. The source of the radon is due to its release from the country rock. It is suggested that the significant $\mathrm{S} 1$ and $\mathrm{S} 2$ tidal signatures of the daily radon (DR) signal, and their variations and modulations, are related to the rotation of the Earth around its axis and around the sun. This indicates a direct link between a component in the solar irradiance (= solar radiation tide) as a driver of the periodic radon signals.

This contribution describes and examines the temporal patterns, at a scale of hours to years, of the radon signal at the Roded site, Southern Arava. The analysis of the temporal patterns combines: (i) qualitative description of the occurrences; (ii) application of time series analysis and signal processing approaches to long (multi-year) and high-resolution $(<1 \mathrm{~h})$ radon time series for the extraction and description of the signal patterns; and (iii) comparative analysis of environmental and eventual geophysical influences on the radon time series.

\section{Geographic and geological setting}

The Roded site (Israel Grid 142350/898000; elevation $285 \mathrm{~m}$ ) is located in the Roded massif, southern Arava, on a block of Precambrian basement (Garfunkel et al., 2000), tectonically uplifted along the western margin of the southern segment of the Dead Sea Transform (DST; Fig. 1). The Roded Massif is influenced by an arid climate $(<$ $50 \mathrm{~mm} /$ year) and the whole area is a rock desert devoid of soil cover.

The local lithology is gneiss and schist intruded by rhyolitic and medium to basic dikes, all belonging to the Precambrian basement. Local metallic mineralization (including low U mineralization) was prospected in the late 1980s (Bogoch et al., 1990), and a prospecting drill hole was placed at the site (Shirav and Bogosh, 1995). The borehole, dipping 


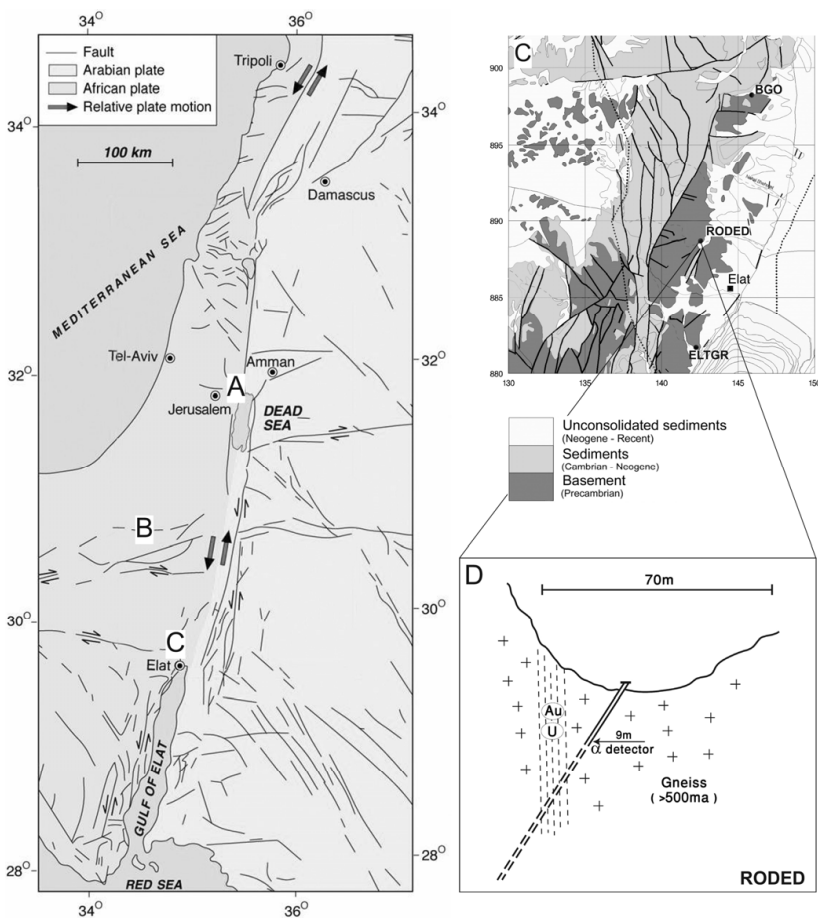

Fig. 1. Location map of arrays of radon monitoring sites along the southern sector of the Dead Sea Transform (DST), separating the Sinai subplate and the Arabian plate. (A) Radon monitoring at the NW shore of the Dead Sea (B) Radon monitoring at Gavnunim (GAV), Makhtesh Ramon, (C) Southern Arava monitoring array: Eilat Granite (ELTGR) sites, Bloch Geophysical Observatory (BGO) in tunnel at Amram, and the RODED site (D) The RODED site - detailed cross-section and monitoring borehole. An alpha detector is inserted into the bottom $(9 \mathrm{~m})$ of the PVC casing. The PVC pipe is blocked at the top to minimize exchange with the atmosphere.

$70^{\circ}$ and 51-56 $\mathrm{m}$ deep, cuts mainly gneiss and some basic dikes. Presently the hole is blocked (rock fall) at a depth of $9 \mathrm{~m}$. A PVC pipe ( $\left.3^{\prime \prime}\right)$ is introduced as a casing to this depth and the radon sensor is lowered to its end. The PVC pipe is blocked at its upper end to inhibit exchange of air in the pipe with the atmosphere.

Initial monitoring of radon in the Southern Arava at the ELTGR and RODED sites (Fig. 1c) indicated temporal variations of radon in the Precambrian basement rocks (Shirav et al., 1999). Monitoring using high-time resolution measurements in this scenario is also performed at three locations covering a sector of around $20 \mathrm{~km}$ along the western margin of the Arava valley - the Roded, Amram and Elat Granite (ELTGR) sites (Fig 1). The phenomena at ELTGR are described in detail by Steinitz at al. (2007) and Barbosa et al. (2007) and initial results from Amram are described by Barobsa et al. (2009). The time series from Roded site, located between these sites, exhibits a temporal pattern which differs from both latter sites. Preliminary monitoring

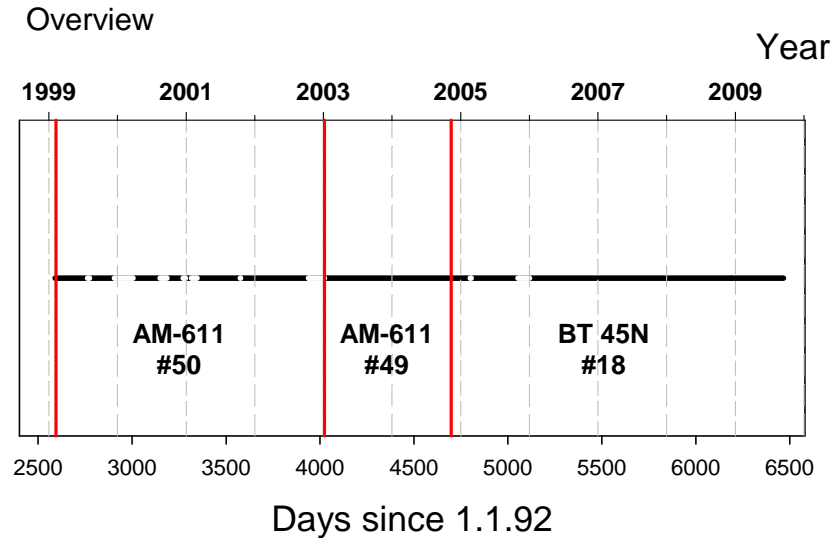

Fig. 2. Overview of the span of the recorded data and the implementation of the different sensors.

Table 1. Sensors used for radon monitoring at Roded site.

\begin{tabular}{lccc}
\hline \multirow{2}{*}{ Sensor } & \multirow{2}{*}{ S/N } & \multicolumn{2}{c}{ Installed } \\
\cline { 3 - 4 } & & Date & Serial day \\
\hline Alpha Nuclear AM-611 & $\# 50$ & 4 Feb 1999 & 2592 \\
Alpha Nuclear AM-611 & $\# 49$ & 7 Jan 2003 & 4024 \\
Barasol BT45 & $\# 018$ & 11 Nov 2004 & 4698 \\
\hline
\end{tabular}

of radon utilizing the SSNTD technology (integral measurements lasting from a week up to one month; Shirav et al., 1999) already indicated the temporal variation of radon level at the shallow depth of $50 \mathrm{~cm}$ at the Roded site.

\section{Methods}

Detection of radon $\left(={ }^{222} \mathrm{Rn}\right)$ at the Roded site is performed with an alpha detector which was replaced during the monitoring (Table 1; Fig. 2). Monitoring was initiated with an alpha detector (Alphameter 611; AlphaNuclear Inc., Canada) based on a $400 \mathrm{~mm}^{2}$ silicon junction diode, immersed in a sensing volume open to the geogas, and equipped with an integral datalogger. Later measurements (since 11 November 2004) were performed with an alpha Barasol BT45 detector $\left(400 \mathrm{~mm}^{2} \mathrm{Si}\right.$ diode; Algade Inc., France), connected to a datalogger (CR10; Campbell Inc.). In both types of instruments the detector is protected from the environment by a thin, aluminized Mylar anti-thoron $\left(={ }^{220} \mathrm{Rn}\right)$ membrane. Radon enters the sensing volume, of about $50 \mathrm{cc}$, by diffusion. Alpha radiation impulses are recorded (as counts) every 15-min. The sensitivity of the instruments is in the order of $50 \mathrm{~Bq} / \mathrm{m}^{3}$ per impulse/hour. Results of temporal variation in ensuing figures are shown on a decimal-day scale (Days since 1 January 1992). 


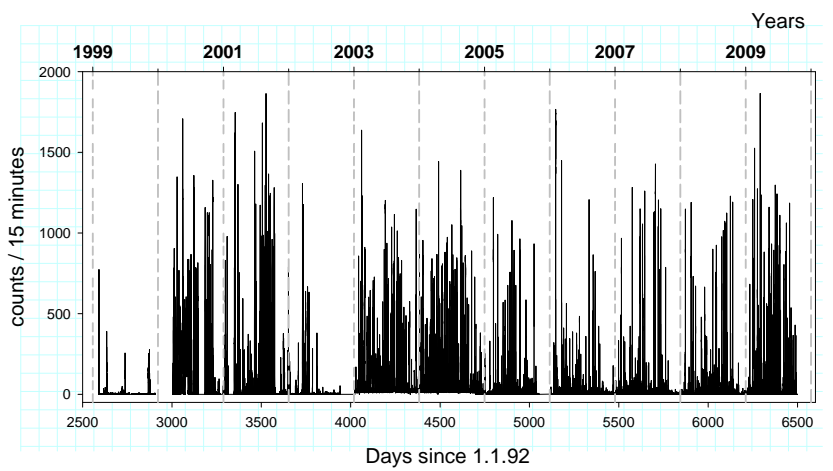

Fig. 3. Time series of radon during 11-years at the Roded site showing the overall variation pattern. Intervals of very low level alternate with times of highly varying signals composed of very strong (SDR) signals. A weak annual modulation is superimposed on this pattern.

\section{Results}

A visual inspection of the radon signal measured at the depth of $9 \mathrm{~m}$ (Fig. 3) exhibits a recurring temporal variation pattern dominated by intense and very fast relative variations and signals. The span of radon variations is from low background levels ( $0-5$ counts per $15 \mathrm{~min}$ ) up to hundreds and more than a thousand counts per $15 \mathrm{~min}$. This variation pattern has been consistent over more than ten years, and is independent of the specific sensor utilized. Part of the overall irregular appearance is due in part to time intervals, lasting from single and several days, and up to tens of days, where a very low signal level is encountered, which is at or below the threshold of the sensor sensitivity (see Fig. 5). These low level intervals interchange with periods where the overall radon level is varying intensely and is extremely high.

Detailed inspection shows that this overall irregular appearing pattern contains systematic temporal variation types spanning from parts of a day to multi-years. These consist of: (a) Long term annual (and semi annual) variations; (b) Medium term multi day variations; and (c) Diurnal and sub-diurnal radon variations. These different types are observed mainly in the time domain and also in the frequencytime domain.

A weak annual variation is evident in some years (Fig. 3). The annual radon (AR) signal is clearly shown in a five year detail using daily averages (Fig. 4), manifested mainly as a superposition on the upper edge of the envelope of the intense variation. Compared with the lowermost baseline levels this variation is actually very large. Moreover, a semiannual constituent is also indicated in some years (2006, 2008; Fig. 4). These annual and semiannual variations are rather obscured due to the intense daily variations discussed below. The long time series (above 10 years) collected in Roded also allows examining the multi-year periodic pattern of the radon time series. Figure 5 shows the FFT spectra of the whole dataset covering the years 1999-2009. An annual periodicity is indicated in the spectrum.

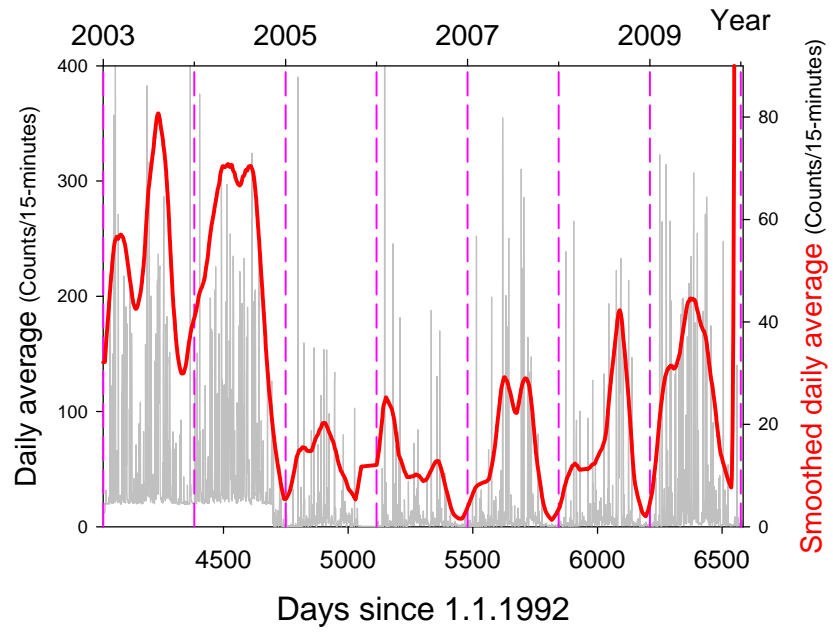

Fig. 4. Seven years of the radon time series at Roded shown using daily averages. The complex and intensively varying signal obliterates an underlying annual radon (AR) signal, which is traceable in the upper envelope of the variation. Smoothing the time series with a two-stage sliding average (51 days and 61 days; Steinitz et al., 2007) emphasizes the AR signal and indicates also a semiannual pattern in some years.

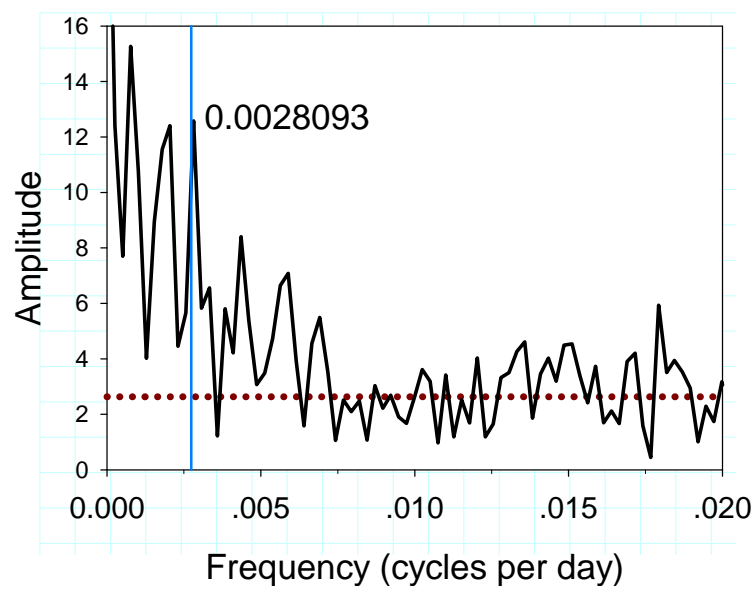

Fig. 5. FFT spectra for an 11-year interval at Roded site. The peak of 0.0028093 cycles per day is a frequency corresponding to the annual periodicity $(1 / 365=0.0027397260$, indicated as a vertical line).

Non-periodic multi-day (MD) signals are described and investigated from radon time series from the ELTR (Fig. 1c; Steinitz et al., 2007) and (Fig. 1b; Steinitz and Piatibratova, 2010). At Roded MD signals occur as groups of sub-daily signals occurring in a train of consecutive days (Fig. 6).

The daily radon (DR) signal at ELTGR and Gavnunim sites (op. cit.) is a significant component of the variations and has basically a semi-sinusoidal form. In Roded the DR signal is the dominant component of the variation. At this site the daily signal is developed only in a part of the day, and 

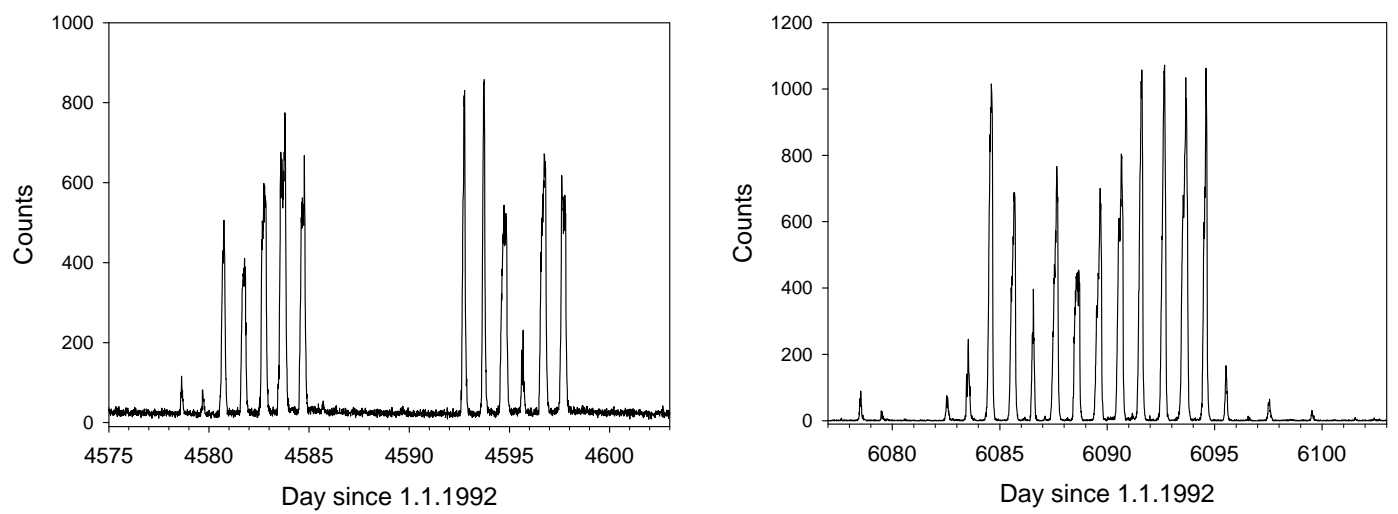

Fig. 6. Times of very low background alternate with days of intense SDR signals. SDR signals occur on some days (left). Multi days (MD) signals are formed by groups of SDR signals occurring on consecutive days (right).
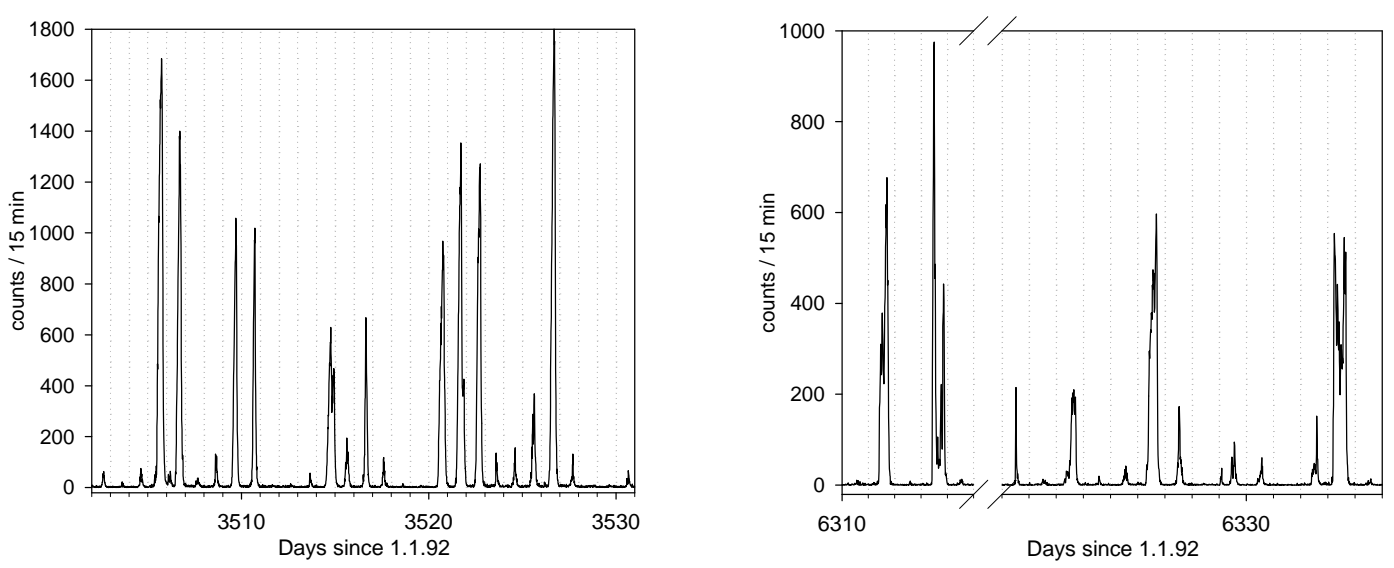

Fig. 7. Time intervals showing isolated and grouped SDR signals with intervening days without any signal (left). In some cases two peaks occur within a day (right).

its form is actually highly non-sinusoidal. Such signals have been termed as Sub Diurnal radon (SDR) signals (Steinitz and Piatibratova, 2010). They occur some days as groups of SDR signals (Fig. 6) or as single and isolated days (Fig. 7). The features of the SDR signal at Roded are:

- Very fast increase of several hours from background level to a sharp peak that typically lasts less than one hour (generally only $15 \mathrm{~min}$ ), followed by a similar fast decrease. The whole time interval from initiation to termination of the SDR signal is generally from 6 to $12 \mathrm{~h}$. The amplitudes of daily peak of the SDR signals vary from several tens of counts to more than one thousand counts per 15-min. Visual inspection of the time series indicates that SDR signal tends to occur at specific hours within a day, indicating a $24-\mathrm{h}$ period.

- Generally one SDR peak occurs in a day. Infrequently a double SDR signal occurs within a single day (Fig. 7, Right). This is an indication for a 12 -h periodic cycle, in addition to the primary 24-h cycle (see below).
For further examination of SDR signals the time of 810 peaks above 100 counts were extracted from the measured time series. This allows analysis of timing of the peak-time within the 24-h daily cycle, as shown in Fig. 8 top. The SDR extreme events, which do not occur every day, exhibit a clear preference to occur between 15h00-16h00 (UT+2), and possibly also around $03 \mathrm{~h} 00-04 \mathrm{~h} 00$. This pronounced timing within the daily cycle is the same for SDR signals of low and high amplitude (Fig. 8 bottom). In both cases a similar distribution of peak time occurs, indicating that there is no relation between peak-time and their intensity.

The peak shape of SDR signals above 100 counts/15-min was investigated. More than $64 \%$ of the peaks are characterised by a decreasing flank which is steeper than the rising flank (Fig. 9a). This asymmetry is accentuated when taking into account only SDR signals of higher amplitude (Fig. 9b). The intense variation in the SDR signal, reflected in the very fast increase followed immediately by a similar fast decrease is further analysed in Fig. 10, showing three typical strong SDR signals with a relatively faster decreasing limb. The 

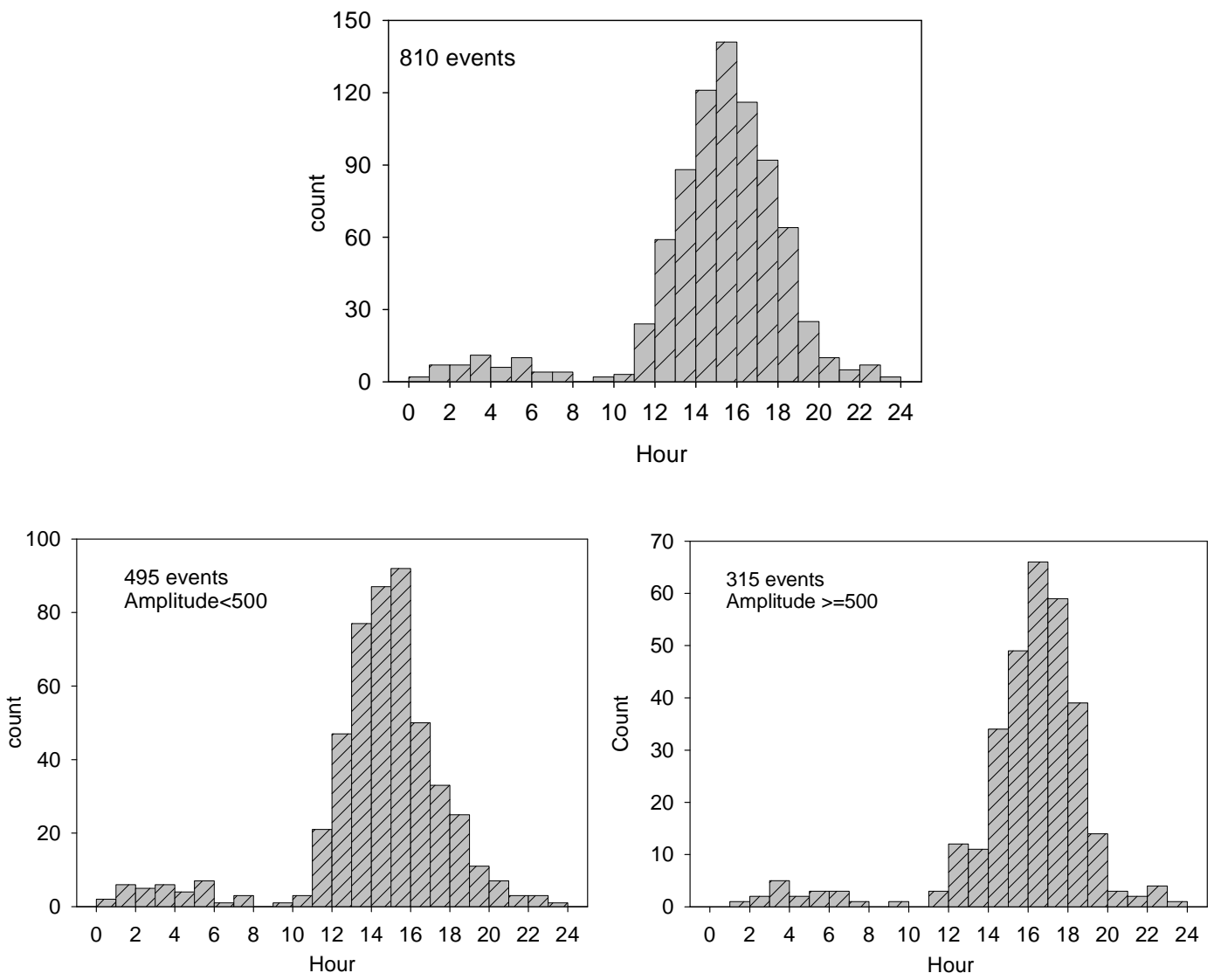

Fig. 8. Distribution of peak time of SDR signals within the 24-h diurnal cycle (top). SDR peaks tend to occur between $15 \mathrm{~h} 00$ and $16 \mathrm{~h}: 00$ $(\mathrm{UT}+2)$. The pattern is the same for SDR signals with low and high amplitudes (bottom).
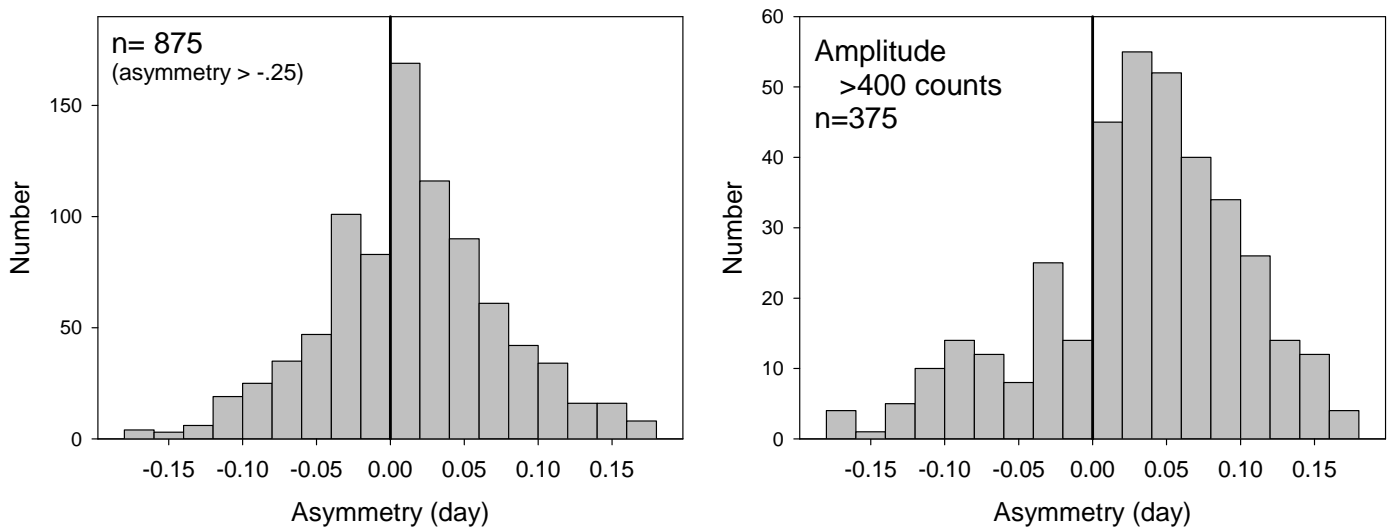

Fig. 9. Peak symmetry distribution (left) indicating the overall faster change of the decreasing limb. The peak symmetry is calculated as the difference of width at half peak height between a decreasing flank symmetric to the rising flank and the actually decreasing flank (see Fig. 10). This incidence of asymmetry is emphasized when considering the relatively intense peaks (right).

decreasing limb was modified by adding a correction based on the radioactive decay of radon from peak-time (indicated). As shown, correcting for the decay of radon does not alleviate this asymmetry.
The diurnal periodicity is further examined using spectral analysis (FFT). Using a long time series at 15-min resolution clearly resolves three periodicities (Fig. 11) at 1-, 2- and 3cycles per day (CPD). These primary periodic constituents reflect the S1 (24h), S2 (12 h) and S3 (8h) tidal frequencies 


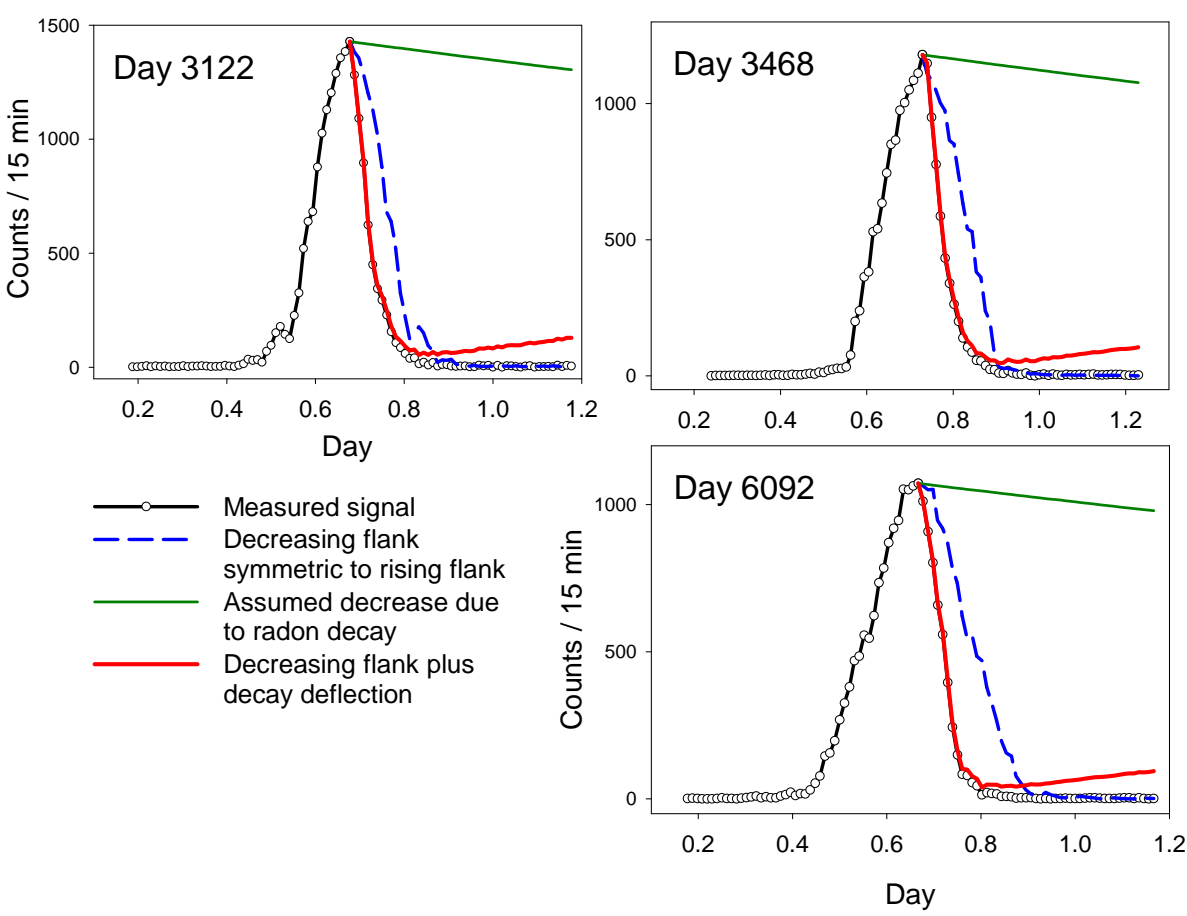

Fig. 10. Examples of intense asymmetric sub-diurnal radon (SDR) signals, having a steeper declining limb. Accounting for the radioactive decay of radon from peak time does not correct the asymmetry (see text).

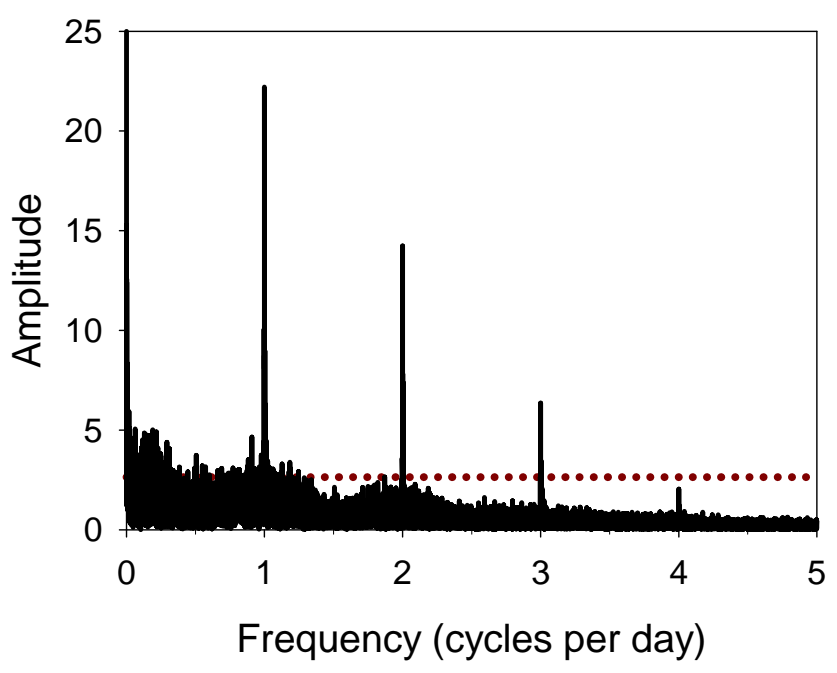

Fig. 11. FFT spectrum of a long (11-year) interval at Roded site showing frequencies of 1-, 2- and 3 cycles per day corresponding to the diurnal S1, S2 and S3 periodicities. Sampling rate is $15 \mathrm{~min}$ and data gaps are filled by linear interpolation.

(Wilhelm et al., 1997). The diurnal tidal constituents typical for gravity $\mathrm{O} 1$ and M2 are absent in the spectra of Roded site.

Relations among the different signals, as compounded phenomena, are highlighted by applying Continuous Wavelet Transform to the long time series. The result in Fig. 12 shows a clear annual structure, strongly related to the 1-CPD fre- quency and also to the 2-CPD. Furthermore, a semi-annual pattern occurs, the relative intensity of which varies among the years. At the diurnal scale, the amplitudes of the daily signal, and possibly a semi-daily constituent are accentuated as a discontinuous horizontal band.

The time series of radon at Roded is clearly non-stationary, indicated by the fact that the mean value changes considerably with time, a situation also encountered in other radon time series (Barbosa et al., 2007). This sets known limitations on the application of Fourier spectral analysis in the combined frequency and time domain to such time series. Thus, further insight on compounded phenomena is gained by addressing a series of shorter time windows and evaluating the spectrum relative to the specific time interval. Therefore, a moving-time-window Fourier spectral analysis is applied to estimate the "local in time" spectrum, as applied by Steinitz et al. (2007) and Steinitz and Piatibratova (2010). The amplitudes of the cyclic pattern are extracted from FFT calculated per 512-h long consecutive intervals (2048 time points $=2^{11}$ ) and plotted relative to the centre of each interval. The resulting time series of the long-term temporal variation of the amplitudes of the daily cyclic constituents is shown in Fig. 13, and for the phase in Fig. 14. The resulting time series exhibits a concordant temporal variation of the amplitude of the diurnal (S1) and semidiurnal (S2) and S3 constituents. All three constituents vary in an annual pattern with maxima in summer, which is in accordance with the result of the CWT analysis (Fig. 12). A gradual 


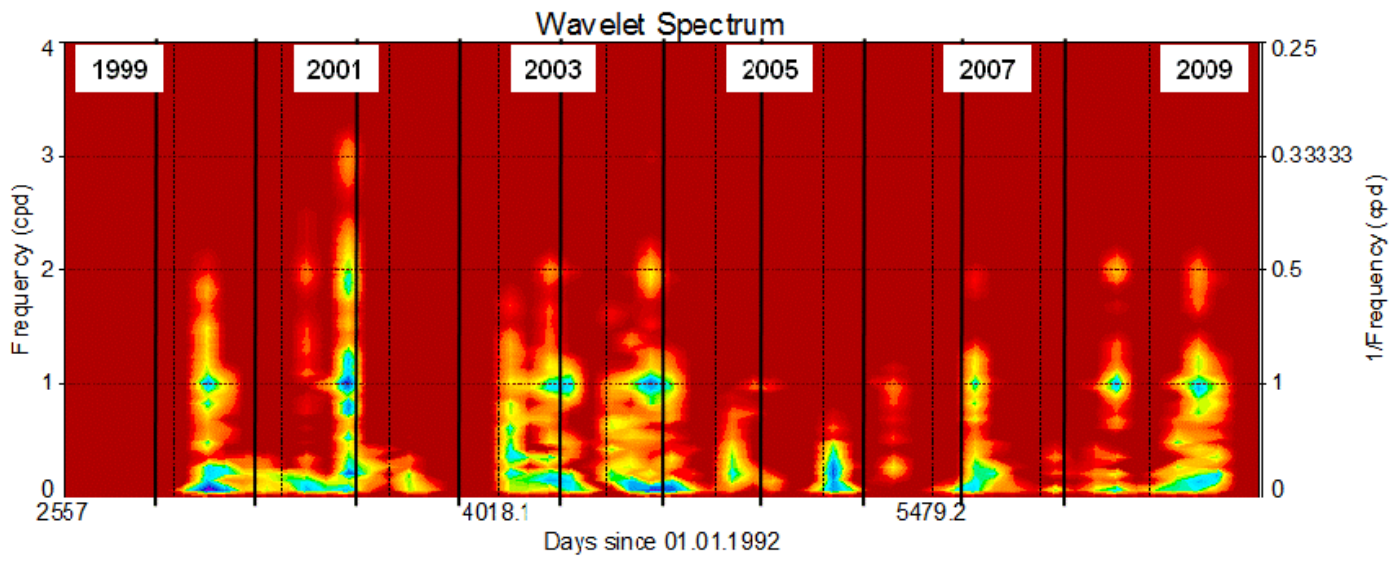

Fig. 12. Continuous Wavelet spectrum of 15-min data during 11 years (1999-2009, annual divisions are shown). Data gaps are filled by linear interpolation. The wavelet model used is Morlet with adjustable parameter $=20$.

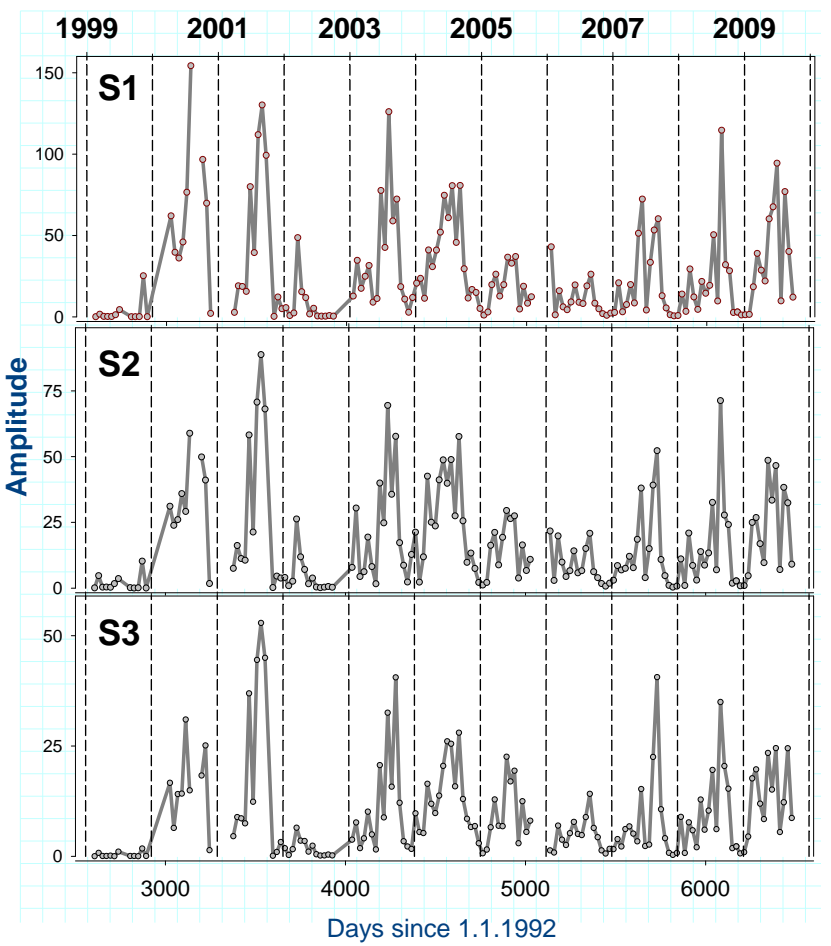

Fig. 13. The temporal variation in the radon signal of the amplitudes of the daily periodic components S1, S2 and S3, is showing: (a) concordance among the sensors of the varying amplitudes and (b) an annual modulation.

long-term (multi-year) variation is exhibited in the corresponding time series of the phase of the three periodic constituents. These parallel trends are clearer from 2003 onwards (probably related to improved continuity of the sampling - compare Fig. 2) and are most clearly depicted in the pattern of S2.

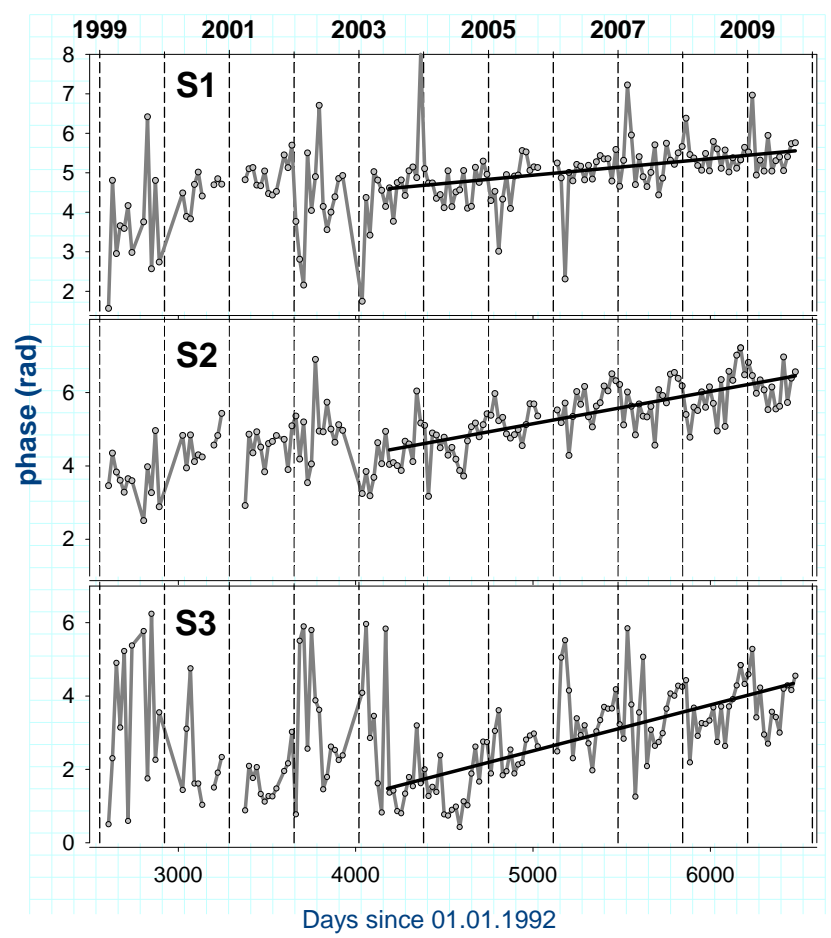

Fig. 14. The temporal variation in the radon signal of the phase of the daily periodic components S1, S2 and S3, showing a similar linear multi-year trend, clearly evident in the last seven years.

\section{Discussion}

The temporal variation of radon in the geological subsurface of southern Israel was recently evaluated in detail at the Elat Granite (ELTGR; Steinitz et al., 2007) and at Gavnunim (GAV; Steinitz and Piatibratova, 2010). The Roded site, some $17 \mathrm{~km}$ north of the ELTGR (Fig. 1), is located between these sites. A mutual evaluation of the results is 
justified as they: (a) Originate from the same geographic and climatic zone, (b) Measurements were performed depths of up to $100 \mathrm{~m}$ in massive magmatic rocks, and (d) Are from the unsaturated zone and at a considerable level above a local water table.

Instrumental effects to explain the phenomena are ruled out based on (a) change of sensors and (b) the systematic nature of the variation patterns, especially in the frequency domain.

The eventual influence of atmospheric parameters - primarily barometric pressure and ambient temperature on the temporal variation - was dealt with separately and in detail for the case of the ELTGR and GAV sites, and similar arguments and conclusions are applicable for the Roded site. A priori, within the specific geographic and geologic regime, there is no reason to assume that the local geogas, composed basically of air, is influenced at depth by advection and transport phenomena. In the massive rock environment atmospheric variations probably leads only to minor local fluctuations at the very shallow level due to above-surface atmospheric variations (mainly pressure). Furthermore, no indications exist as to active geogas flow in this region. Several additional criteria can be raised in the case of the Roded site:

1. Annual variation which is a prominent component in atmospheric variation is highly obscured in the measured signal at Roded.

2. It is impossible to account for the SDR signals, the primary component of the variation, as driven by atmospheric variations.

3. A systematic multi-year variation of the phase of the diurnal periodicities cannot be due to an atmospheric variation.

Thus, it is concluded that atmospheric parameters cannot be considered as the drivers of the signals at these subsurface geological environments.

A similar argument is raised to negate the influence of active geodynamic processes. The site is indeed located in the marginal zone of the DST but, as far as we know, it is not affected by active geodynamic processes. If one could at all raise the possibility that the short-term SDR signals are related to seismicity. This is discarded on the grounds that there is no local seismic activity of such a pattern and that seismic events are non-periodic at the diurnal scale. Furthermore, the lack in the daily cycle of frequencies indicative for gravity tide (O1, M2) excludes such a mechanically generated influence, either via the solid earth or even via the geogas system. All this negates mechanical processes as drivers of a varying emanation of radon from the solid.

The high variability encountered at Roded is due to the predominance of the SDR signal. Major questions are raised when trying to evaluate the nature of the driver of SDR signals at Roded. The SDR signals are recorded by an alpha detector the sensing volume of which is in the order of $50 \mathrm{cc}$. Radon entres the sensing volume by diffusion from the immediate vicinity - from the geogas around the bottom end of the PVC pipe in the case of this site. In such a scenario the concentration of radon in the sensing volume reflects the concentration in the adjacent volume of geogas. The local background due to emanation from rocks in the vicinity of the sensor is probably represented by the low level readings (in the order of $50 \mathrm{~Bq} / \mathrm{m}^{3}$ ) during longer intervals of up to several tens of days. Initiating the extremely fast rise of the signal is incompatible with diffusion rates and must mean a flow of radon rich geogas from another zone, to the immediate vicinity of the sensor, which is followed by a similar flow of geogas with no radon - where the (interpreted) concentration differences attain several orders of magnitude. Two end member patterns of flow can be thought off: a continuous flow of a carrier geogas with highly varying concentrations of radon or, alternatively, a discontinuous flow alternating between radon rich and radon deficient concentration. Flow patterns with such variability are highly improbable on the following grounds:

1. The flow patterns which always generate an extremely short peak time lasting an hour or less are highly improbable.

2. If such flow patterns exist they are not limited to the site (borehole) alone and must be of an extensive scale. No geological or geo-environmental evidence is known to support this.

3. The highly significant daily periodicity of the supposed flow events, the timing of which is determined by an external above surface driver.

Negating a flow regime involving very regular temporal features raises the possibility that the SDR signal does not reflect actual variation in the concentration of radon in the adjacent geogas but rather changes in the radiation from radon within the sensing volume. This is further discussed below.

SDR signals have also been documented from the GAV site, where they are recoded (by a similar detector) at a depth of $85 \mathrm{~m}$. In both Roded and GAV sites the signals occur in some days and reflect sub-daily intense variations. A central property common for both occurrences is their unambiguous occurrence within the 24-h cycle. A major difference is that at GAV a bi-modal daily distribution is observed while at Roded a uni-modal pattern at observed. Subsurface geophysical periodic drivers are not known. At both sites such daily patterns must be reflecting an above surface periodic geophysical driver possessing typical tidal frequencies. This conclusion is supported by the spectral analysis which demonstrates that the involved periodicities are the tidal constituents S1, S2 and S3. If such a common feature is at hand then the differences in occurrence and timing pattern among the two sites may be attributed to local, i.e., geological, interactions. 
In terms of fundamental properties the signal types and phenomena at Roded are in accordance with variation patterns found at the other locations in Israel. The source of the radon in the geogas is from the local country rock. In general the drivers so far suggested for explaining such radon signals are: (a) A process acting on the rock and affecting the release (emanation and exhalation) of radon from the solid and its transfer into the gas phase; (b) Processes affecting the level of radon in the gas phase, such as mass transfer and transport, mixing, dilution and adsorption. The above mentioned considerations suggest that such processes are incompatible for the generation of the described radon signals. On the other hand, the patterns of temporal variation of radon place them within the realm of features observed in geophysical time series. Having excluded both subsurface geodynamic processes and above surface atmospheric influences a different option is considered to explain features in the temporal variation of radon at Roded. In the case of the ELTGR and GAV sites (op. cit.), it was suggested that the generation of the periodic phenomena in radon time series is linked to an interaction with a component in solar radiation tide. This suggestion is further substantiated for the signal patterns at Roded, using similar criteria based on the characteristics of the radon time series in the frequency and frequency-time domains:

- The peak times of SDR signal clearly indicate a diurnal periodicity

- Predominance of the S1, S2 and S3 periodicities, and

- The lack of diurnal periodicities indicative for gravity tidal interaction $(\mathrm{O} 1, \mathrm{M} 2)$.

- Generation of diurnal periodicities in the radon system is related to the rotation of Earth around its axis

- The amplitude of the diurnal frequencies S1, S2 and S3 are co-modulated in an annual pattern, with high amplitudes in summer. Generation of this periodicity, as a compounded feature in the frequency-time domain, is related to the rotation of Earth around the sun.

These features at Roded are common to similar features at ELTGR and GAV. In line with the interpretation suggested for the latter cases it is, therefore, concluded that this is also in the case of the Roded site.

Acknowledgements. N. Gazit, L. Michaeli and U. Malik assisted with the data collection and in initial processing. We would like to thank our colleagues H. Zafrir and S. Barbosa for their joint discussions. The project is supported by Israel Science Foundation grant ISF 524/05.

Edited by: C. Gaina

\section{References}

Alparone, S., Behncke, B., Giammanco, S., Neri, M., and Privitera, E.: Paroxysmal summit activity at Mt. Etna (Italy) monitored through continuous soil radon measurements, Geophys. Res. Lett., 32, L16307, doi:10.1029/2005GL023352, 2005.

Aumento, F.: "Radon tides" on an active volcanic island: Terceira, Azores, Geofísica Internacional, 41, 499-505, 2002.

Ball, T. K., Cameron, D. G., Colma, T. B., and Roberts, P. D.: Behavior of Radon in the geological environment: a review, Q. J. Eng. Geol., 24(2), 169-182, 1991.

Barbosa, S. M., Steinitz, G., Piatibratova, O., Silva, M. E., and Lago, P.: Radon variability at the Elat granite, Israel: Heteroscedasticity and nonlinearity, Geophys. Res. Lett., 34, L15309, doi:10.1029/2007GL030065, 2007.

Barbosa, S. M., Steinitz, G., Zafrir H., and Malik, P. O.: Radon variability in a subsurface stable environment - insights from continuous monitoring at the Bloch Geophysical Observatory, Har Amram, southern Israel, Geol. Soc., Annu. Meet., Kfar Blum, Abstracts of submitted papers, p. 124, 2009.

Begin, Z. B. and Steinitz, G.: Temporal and spatial variations of micro-earthquake activity along the Dead Sea Fault, 1984-2004, Israel Jour. Earth Sci., 54, 1-14, 2005.

Bogoch, R., Gilat, A., Avigad, D., Zohar, E., Shirav, M., and Halicz, L.: The Millstone gold anomaly, Roded prospect area: summary and evaluation, Isr. Geol. Surv. Rep. GSI/47/90, 42 pp., 1990.

Burton, M., Neri, M., and Condarelli, D.: High spatial resolution radon measurements reveal hidden active faults on Mt. Etna, Geophys. Res. Lett., 31, L07618, doi:10.1029/2003GL019181, 2004.

Cicerone, R. D., Ebel, J. E., and Britton, J.: A systematic compilation of earthquake precursors, Tectonophysics, 476(2009), 371396. 2009.

Cigolini, C., Salierno, F. Gervino, G., Bergese, P., Marino, C., Russo, M., Prati, P., Ariola, V., Bonetti, R., and Begnini, S.: High-Resolution Radon Monitoring and Hydrodynamics at Mount Vesuvius, Geophys. Res. Lett., 20, 4035-4038, 2001.

Cigolini, C., Poggi, P, Ripepe, M., Laiolo., M., Ciamberlini, C., Delle Donne, D., Ulivieri, G., Coppola, D., Lacanna, G., Marchetti, E., Piscopo, D., and Genco, R.: Radon surveys and real-time monitoring at Stromboli volcano: Influence of soil temperature, atmospheric pressure and tidal forces on ${ }^{222} \mathrm{Rn}$ degassing, J. Volcanology Geothermal Res., 184, 381-388, 2009.

Crockett, R. G. M., Gillmore, G. K., Phillips, P. S., Denman, A. R., and Groves-Kirkby, C. J.: Tidal synchronicity of builtenvironment radon levels in the UK, Geophys. Res. Lett., 33, L05308, doi:10/1029/2006GL027074, 2006.

Finkelstein, M., Eppelbaum, L. V., and Price, C.: Analysis of temperature influences on the amplitude frequency characteristics of Rn gas concentration, J. Environ. Radioactivity, 86, 251-270, 2006.

Garfunkel, Z., Eyal, Y., Weissbrod, T., Bakler, N., Shimorn, A. E., Peltz, S., Gukin, V., Bartov, Y., Druckman, Y., Rosensaft, M., and Sneh, A.: Geological Map of the Northern Gulf of Elat area, 1:100 000, Geological Survey of Israel, 2000.

Groves-Kirby, C. J., Denman, A. R., Crockett, R. G., Phillips, P. S., and Gillmore, G. K.: Identification of tidal and climatic influences within domestic radon time series from Northamptonshire, UK, Sci. Tot. Environ., 367, 191-202, 2006.

Hartmann, J. and Levy, J. K.: Hydrogeological and gas geochemical 
earthquake precursors - A review for application, Nat. Hazards, 34, 279-304, 2005.

Immè, G., La Delfa, S., Lo Nigro, S., Morelli, D., and Patane, G.: Soil radon monitoring in the NE flank of Mt. Etna (Sicily), Appl. Radiat. Isotopes, 64, 624-629, 2006.

Monin, M. M. and Seidel, J. L.: Radon in soil-air and groundwater related to major geophysical events: a survey. Nuclear Instruments and Methods in Physics Research. Section A: Accelerators, Spectrometers, Detectors and Associated Equipment, 314(2), 316-330, 1992.

Pinault, J. L. and Baubron, J. C.: Signal processing and diurnal and semidiurnal variations in radon and atmospheric pressure: $\mathrm{A}$ new tool for accurate in situ measurement of soil gas velocity, pressure gradient and tortuosity, J. Geophys. Res., 102, 1810118120, 1997.

Segovia, N., Mena, M., Seidel, J. L., Monnin, M., Tamez, E., and Pena, P.: Short and long term radon in soil monitoring for geophysical purposes, Radiation Measurements, 25(1-4), 547-552, 1995.

Shapiro, M. H., Rice, A., Mendenhall, M. H., Melvin, J. D., and Tombrello, T. A.: Recognition of environmentally caused variations in Radon time series, Pure Appl. Geophys., 122, 311-326, 1985.

Shirav, M. and Bogosh, R.: Preliminary report on borehole cores, Roded prospect area, Isr. Geol. Surv., Rep. GSI/14/95, 12 p., 1995.

Shirav, M., Steinitz, G., and Vulkan, U.: Feasibility of Rn monitoring in a tectonic context - testing in the Elat area, Isr. Geol. Surv. Rep. TR-GSI/4/99, 8 p., 1999 (in Hebrew).

Steinitz, G., Vulkan, U., Lang, B., Gilat, A., and Zafrir, H.: Radon emanation along border faults of the Rift in the Dead Sea area, Israel J. Earth Sci., 41, 9-20, 1992.
Steinitz, G., Vulkan, U., and Lang, B.: Monitoring of the tectonically related radon flux in Israel, Isr. Geol. Surv. Current Res., 10, 148-153, 1996.

Steinitz, G., Vulkan, U., and Lang, B.: The Radon flux at the northwestern segment of the Dead Sea (Dead Sea Rift) and its relation to earthquakes, Israel J. Earth-Sci., 48, 283-299, 1999.

Steinitz, G., Begin, Z. B., and Gazit-Yaari, N.: A Statistically Significant Relation between Rn Flux and Weak Earthquakes in the Dead Sea Rift Valley, Geology, 31, 505-508, 2003.

Steinitz, G., Piatibratova, O., and Barbosa, S. M.: Radon daily signals in the Elat Granite, southern Arava, Israel, J. Geophys. Res., 112, B10211, doi:10.1029/2006JB004817. 2007.

Steinitz, G. and Piatibratova, O.: Radon signals in the Gavnunim intrusion, Makhtesh Ramon, Israel, Geophys. J. Int., 180, 651665, 2010.

Toutain, J. P. and Baubron, J. C.: Gas geochemistry and seismotectonics: a review, Tectonophysics, 304, 1-27, 1999.

Trique, M., Richon, P., Perrier, F., Avouac, J.-P., and Sabroux, J.C.: Radon emanation and electric potential variations associated with transient deformation near reservoir lakes, Nature, 399, 137-141, 1999.

Weinlich, F. H., Faber, E., Bouskova, A., Horalek, J., Teschner, M., and Poggenburg, J.: Seismically induced variations in Marianske Lazne fault gas composition in the NW Bohemian swarm quake region, Czech Republic - A continuous gas monitoring, Tectonophysics, 421, 89-110, 2006.

Wilhelm, H., Zürn, W., and Wenzel, H. G. (Eds.): Tidal phenomena, Lectures in Earth Sciences (Springer), 66, 398 p., ISNBN 3-54062833-9, 1997. 